\title{
An Alternative Method of Forecasting Divorce Rates Based on the Parametric Sickle Model
}

\author{
Nicholas H. Wolfinger \\ Department of Family and Consumer Studies, \\ University of Utah
}

Under peer review at Meta-Psychology, submission number MP2018.891. Anyone can participate in peer review by sending the editor an email, or through discussion on social media. The preferred way of open commenting, however, is to use the hypothes.is integration at SocArXiv and directly comment on this preprint.

Editor: Rickard Carlsson, rickard.carlsson@Inu.se

Website: https://open.Inu.se/index.php/metapsychology

"Correspondence to Nicholas H. Wolfinger, Department of Family and Consumer Studies, 225 South 1400 East, AEB 228, University of Utah, Salt Lake City, UT 841120080 (e-mail: Nick.Wolfinger@fcs.utah.edu). I thank Joshua Goldstein, William M. Mason, and Ken Smith for helpful suggestions. 



\title{
An Alternative Method of Forecasting Divorce Rates \\ Based on the Parametric Sickle Model
}

\begin{abstract}
Demographers routinely predict that between 40 and 50 percent of new marriages will end in divorce. Based on life tables, these forecasts entail strong assumptions that current marriages will behave in the future like others did in the past. I use data from the 1995 June Marriage and Fertility Supplement of the Current Population Survey to test an alternative method of forecasting divorce rates: predictions based on the parametric sickle model of marital instability. The sickle model corresponds almost perfectly to completed marriage cohorts (30 year marriages unlikely to ever dissolve), but offered implausibly low divorce rate forecasts for newer marriages. It is therefore unlikely to be useful for forecasting divorce rates.
\end{abstract}




\section{INTRODUCTION}

One of the most commonly encountered statistics in family demography is the estimate of current divorce rates: almost one out of two new marriages will fail. Although the divorce rate has fallen since the 1970s (Goldstein 1999; United States Bureau of the Census 2001), recent studies still produce estimates of marital failure somewhere between 40 and 50 percent (Miller 2014).

Forecasting divorce rates necessarily involves predicting future behavior from past behavior. Like earlier studies, recent forecasts were computed using life tables. Although well understood, the assumptions involved are not always acknowledged. For each year of marriage, the probability of failure is based on previous marriages surviving to that year. Life tables therefore entail strong assumptions that future behavior will somehow resemble past and present behavior, assumptions that may not be tenable in a time of falling divorce rates.

In this paper I develop an alternative method of forecasting divorce rates, based on a parametric approximation of the hazard of marital failure. The so-called sickle model has been used to model the predictors of divorce (e.g., Diekmann and Engelhardt 1999; Fu and Wolfinger, 2011; Wolfinger 2000, 2003, 2005), but not to forecast divorce rates. Goldstein and Kenney (2001) demonstrated the utility of using parametric models to predict time-dependent family processes. They showed that the Hernes parametric model fit well with the observed distribution of the lifetime chances of entering a first marriage. Can the sickle model offer corresponding forecasts of divorce that outperform life tables?

The divorce rate has implications for both individuals and society. Divorce is often a deeply traumatic event for both parents and children (Clarke-Stewart \& Brentano, 2006; Wolfinger, 2005). It also has noteworthy economic consequences, frequently leaving women impoverished (McKeever \& Wolfinger, 2001, 2005, 2013). 
Furthermore, divorce has at times been central to current policy debates on family wellbeing, particularly in light of covenant marriage laws recently enacted in Louisiana, Arizona, and Arkansas (Nock et al. 2008). Similar legislation was introduced in over 30 states in the 1990s (Gardiner, Fishman, Nikolov, and Laud 2002); language urging the reconsideration of no-fault divorce appeared in the 2000 Republican Platform (New York Times 2000).

\section{METHODS}

I analyze data from the 1995 June Marriage and Fertility Supplement of the Current Population Survey (CPS), a nationally representative sample of approximately 50,000 households in the United States. Event histories of first marriage duration are analyzed; second marriages have higher divorce rates and therefore merit separate investigation (Martin and Bumpass 1989; Bramlett and Mosher 2001; Kreider and Fields 2001). Only female marital histories are examined, because men are much more likely to deny their own divorces (Mitchell, 2010). Separation rather than divorce effectively marks the end of most marriages (Ono 1995), so event histories are based on separation dates. Marriages ending in spousal death are censored, as are those intact at the time of data collection. Weighted and unweighted analyses produce almost identical results, so the unweighted estimates are presented.

I compare forecasts of divorce rates computed using life tables and the sickle model, a parametric model of duration dependence that better approximates the hazard of marital failure than any other unimodal parametric hazard function (Diekmann and Mitter 1984). The sickle model, shown in Figure 1, captures the nonmonotonic risk of divorce, which increases during the first few years of marriage and then slowly declines. This hazard function reflects the adjustment-commitment cycle of early marriage: the 
divorce rate initially rises as couples establish compatibility. After peaking, the odds of divorce decline as marriage length increases. Over time commitment grows and incrementally decreases the likelihood of divorce. Furthermore, the divorce rate continues to decline because previous exposure to the comparably unstable early years of marriage has removed ill-fated unions from the at-risk pool. The sickle model also has the attractive feature of a defective distribution: it can account for the fact that some couples will never divorce. The sickle model has a transition rate defined as

$r(t)=a t \exp \left\{-\frac{t}{b}\right\}, a=\exp \left(\alpha_{0}\right), b=\exp \left(\beta_{0}\right)$

with survivor function

$$
G(t)=\exp \left\{-a b\left[b-(t+b) \exp \left(-\frac{t}{b}\right)\right]\right\}, a=\exp \left(\alpha_{0}\right), b=\exp \left(\beta_{0}\right)
$$

In these equations, $t$ represents marriage duration while $a$ and $b$ are constants. The $a$ constant reflects the relative level of divorce risk, while $b$ governs the curvature of the sickle. Sickle model forecasts of divorce rates are estimated using maximum likelihood via the TDA statistics package (Rohwer 1994; Blossfeld and Rohwer 1995). Since all computed forecasts in my analysis are based on large samples, the corresponding asymptotic t-statistics are all greater than 50 . Accordingly I do not present confidence intervals.

\section{Figure 1 Here}

Martin and Bumpass (1989) suggest that divorce rates calculated from CPS data are biased downwards for various reasons. Since any bias should apply equally to both life table and sickle model estimates, no correction is attempted. Accordingly the results presented here should be viewed as underestimates of the "true" divorce rate. For 
similar reasons I do not compute separate estimates based on race, education, or other demographic variables. My objective of contrasting different methods for forecasting divorce rates can best be facilitated with population-wide estimates.

\section{RESULTS}

3.1 Is the sickle model suited to forecasting divorce rates?

Diekmann and Mitter (1984) show that the sickle model approximated the observed divorce rate in the United States for marriage cohorts between 1949 and 1962. I update this result by contrasting observed and predicted cumulative divorce rates for women marrying between 1965 and $1969(\mathrm{~N}=3,959)$. Few couples divorce after 30 years of marriage, so this comparison allows insight into a largely "completed" marriage cohort (cf. Wolfinger 2011). Figure 2 shows how sickle model estimates of cumulative divorce rates compare with observed divorce rates across the 30 year period. At no point do the two methods produce estimates differing by more than $1 \%$. After 30 years, both show an identical cumulative divorce rate of just under $40 \%$. This result confirms that the sickle model approximates the observed hazard of marital dissolution.

\section{Figure 2 Here}

\subsection{Contrasting life table and sickle forecasts of 30 year divorce rates}

One difficulty in forecasting from parametric models is deciding how much data to use. Several years of marital histories may not provide enough information to forecast accurate 30 year divorce rates. Forecasting from too many years results in the reproduction of the observed rate, as the results reported in Figure 2 demonstrate. 
Estimates based on many years of data also have the problem of conflating different period-specific divorce rates. This is particularly relevant given recent declines in divorce. Between 1985 and 1995, for instance, the annual number of divorces per 1,000 married women age 15 and over declined from 21.7 to 19.8 (United States Bureau of the Census 2001). Sickle model-based forecasts drawing on too many years of recent data will therefore be biased upwards.

For these reasons I compute three separate sickle model forecasts of 30 year divorce rates, based on the five, ten, and 15 most recent years of marital histories from the CPS. The results are shown in Figure 3. Along with each forecast I plot the observed cumulative divorce rate for the years of data (five, ten, or 15) used to compute each forecast.

\section{Figure 3 Here}

The three forecasts yield 30 year cumulative divorce rates that range from $21 \%$ to $36 \%$, all substantially lower than the corresponding life table estimate of $47 \%$. The forecasted divorce rates vary inversely with the number of years on which the forecast is based: the forecast based on 15 years of data yields the highest divorce rate, $36 \%$, while that based on five years of data suggests an improbably low divorce rate of $21 \%$. For all three, the forecasted rates adhere to the observed rates for the corresponding years of data employed. However, the observed and forecasted rates show signs of diverging for the final years of observed divorce rates; the divergence is particularly acute for the five year forecast. Coupled with the low forecasts based on five and ten years of data, the direction of the divergence suggests that the sickle model is underpredicting divorce rates.

\subsection{How well did the sickle model perform?}


Although Figure 2 shows that the sickle model fits completed marriage cohorts well, it forecast artificially low divorce rates. To test the performance of the sickle model forecasts based on ten and 15 years of marital histories, I compute additional forecasts of 30 year divorce rates for various completed marriage cohorts. These are contrasted with the corresponding observed 30 year divorce rates to determine the accuracy of sickle model forecasts. The results of this exercise are shown in Table 1. The earliest year of marriage represented in the 1995 CPS is $1942 ; 1960-1969$ and $1955-1969$ are the last respective decadal and 15 year marriage cohorts for which 30 year divorce rates can be observed that reflect at least half of the cohort under consideration. No diagnostic comparisons are presented for forecasts based on five years of data, given their poor performance.

\section{Table 1 Here}

The 15 year sickle model forecasts are uniformly (in)accurate: all three underestimate the true 30 year divorce rates by $4 \%$. Applying this figure to the 30 year sickle model forecast of the divorce rate for the 15 most recent years of CPS data $(1981-1995)$ yields a predicted divorce rate of $40 \%(36+4)$. This is somewhat lower than the corresponding 30 year life table estimate of $47 \%$.

The sickle model forecasts based on ten years of data show greater variation: according to Table 1 the cohort-specific rates of over-prediction range from $10 \%$ to $6 \%$, with the latter figure representing the most recent cohort, 1960-1969. Therefore the ten year sickle model forecasts appear to be performing better over time. Although three data points hardly provide incontrovertible evidence of a trend, this result is consistent with Diekmann and Mitter (1984); they also find that the sickle model performs better for more recent marriage cohorts. Assume, then, that $6 \%$ represents the degree to which 
the sickle model forecast based on ten years of marital histories under-predicts the true divorce rate. Based on the last completed decadal marriage cohort (1960-1969), the $6 \%$ assessment of underreporting for ten year sickle model forecasts is conservative; it is entirely possible that they have become more accurate. Applying the $6 \%$ figure to the 30 year sickle model forecast of the divorce rate for the ten most recent years of CPS data (1986-1995) yields a predicted divorce rate of $35 \%(29+6)$. Thus both the ten and 15 year sickle model forecasts suggest lower divorce rates than the corresponding 30 year life table estimates.

Why do the corrected ten and 15 year sickle model forecasts, respectively $35 \%$ and $40 \%$, differ? There are two possible explanations. First, the 15 year forecast may be more reliable, since it is based on longer marital histories. Second, the difference could reflect declines in the divorce rate occurring between 1981 and 1985, years of marital histories used only in computing the 15 year forecast. Perhaps the 30 year cumulative divorce rate declined $5 \%$ in these years.

\section{CONCLUSION}

This paper presents an alternative to life table forecasts of marital dissolution rates: the parametric sickle model. Although the sickle model underestimates the divorce rate, the corrected forecasts of $35 \%$ (based on ten years of marital histories) and $40 \%$ (based on 15 years) are both lower than the corresponding life table estimate of $47 \%$. Lest it seem insignificant, note that a $7-12 \%$ difference means millions of fewer divorces. Based on these results the assumption that one half of all first marriage will dissolve is undeservedly pessimistic. It's consistent with this assessment that the divorce rate has continued to decline since 1995 (Norén 2009), the last year the June CPS collected event history data on marriage.

Which figure is correct, $35 \%, 40 \%$, or the life table estimate of $47 \%$ ? Since all 
three are forecasts, there is no way of knowing for sure until 30 years in the future when the current marriage cohort is completed. Each figure draws on a different set of assumptions. Life table forecasts imply that the past is prologue. In contrast, the sickle model forecasts presented here rely on only the ten and 15 most recent years of marital data, they do not reflect the dramatic surge in the divorce rate occurring between 1965 and 1980. Life table forecasts draw more heavily on the past and are accordingly constrained by it.

The sickle model forecasts need not be totally accurate to be of interest; they need only cast doubt on life table estimates of the divorce rate, by suggesting that they exaggerate the number of new marriages likely to fail. Perhaps the divorce rate is not as high as has generally been accepted. 


\section{REFERENCES}

Blossfeld, H.P. and G. Rohwer. 1995. Techniques of event history modeling: New approaches to causal analysis. Mahweh, NJ: Erlbaum.

Bramlett, M.D. and W.D. Mosher. 2001. First Marriage Dissolution, Divorce, and Remarriage: United States. Advance data from vital health statistics; no. 323. Hyattsville, MD: National Center for Health Statistics.

Bumpass, L.L., T.C. Martin, and J.A. Sweet. 1991. "The Impact of Family Background and Early Marital Factors on Marital Disruption." Journal of Family Issues 12:2242.

Bianchi, S.M., L. Subaiya, and J. Kahn. 1999. "Economic Well-Being of Husbands and Wives after Marital Disruption." Demography 36:195-203.

Clarke-Stewart, A., \& Brentano, C. (2006). Divorce: Causes and consequences. Yale University Press.

Diekmann, A. and H. Engelhardt. 1999. "The social inheritance of divorce: Effects of parent's family type in postwar Germany." American Sociological Review 64:783793.

Diekmann, A. and P. Mitter. 1984. "A Comparison of the "Sickle Function" with Alternative Stochastic Models of Divorce Rates." Pp. 123-153 in Stochastic Modeling of Social Processes, edited by A. Diekmann and P. Mitter. Orlando: Academic Press, Inc.

Fu, V. K. and N. H. Wolfinger. 2011. "Broken Boundaries or Broken Marriages? Racial Intermarriage and Divorce." Social Science Quarterly 92:1096-1117. 
Gardiner, K., M. Fishman, P. Nikolov, and S. Laud. 2002. "State Policies to Promote Marriage." Preliminary report submitted to the U.S. Department of Health and Human Services, Office of the Assistant Secretary for Planning and Evaluation.

Goldstein, J.R. 1999. "The Leveling of Divorce in the United States." Demography 36:409-414.

Goldstein, J. R., \& Kenney, C. T. (2001). Marriage delayed or marriage forgone? New cohort forecasts of first marriage for US women. American Sociological Review, 506-519.

Kreider, R.M. and J.M. Fields. 2001. Number, Timing, and Duration of Marriages and Divorces: Fall 1996. Current Population Reports, P70-80. Washington, DC: U.S. Census Bureau.

Martin, T.C. and L.L. Bumpass. 1989. "Recent Trends in Marital Disruption." Demography 26:37-47.

McKeever, M., \& Wolfinger, N. H. (2001). Reexamining the economic costs of marital disruption for women. Social Science Quarterly, 82(1), 202-217.

McKeever, M., \& Wolfinger, N. H. (2005). Shifting Fortunes in a Changing Economy. In Fragile families and the marriage agenda (pp. 127-157). Springer, Boston, MA.

McKeever, M., \& Wolfinger, N. H. (2012). Over the long haul: The persistent economic consequences of single motherhood. In Economic stress and the family (pp. 139). Emerald Group Publishing Limited.

Mitchell, C. (2010). Are divorce studies trustworthy? The effects of survey nonresponse and response errors. Journal of Marriage and Family, 72(4), 893-905.

New York Times. 2000. "The Republicans; Excepts from Platform Approved by 
Republican National Convention." August 1, 2000.

Nock, S.L., J.D. Wright, and L. Sanchez. 1999. "America's divorce problem." Society $36: 43-52$.

Norén, Laura. 2009. "Divorce rate trends - selective framing."Graphic Sociology blog, available at https://thesocietypages.org/graphicsociology/2009/12/24/divorcerate-trends-selective-framing/.

Rohwer, G. 1994. TDA working papers. Bremen: University of Bremen.

Ono, H. 1995. "Expanding on Explanations of Recent Patterns in U.S. Divorce Rates." Unpublished doctoral dissertation, Department of Sociology, UCLA.

Smock, P.J. 1993. "The Economic Costs of Marital Disruption for Young Women Over the Past Two Decades." Demography 30:353-371.

-----. 1994. "Gender and the Short-Run Consequences of Marital Disruption." Social Forces 73:243-262.

Stewart, A.J., A.P. Copeland, N.L. Chester, J.E. Malley, and N.B. Barenbaum. 1997. Separating Together: How Divorce Transforms Families. New York: The Guilford Press.

Thompson, R.A. and J.M. Wyatt. 1999. "Values, Policy, and Research on Divorce: Seeking Fairness for Children." Pp. 191-232 in The Postdivorce Family: Children, Parenting, and Society, edited by R.A. Thompson and P.R. Amato. Thousand Oaks, CA: Sage.

United States Bureau of the Census. 2001. Statistical Abstract of the United States: 2001 (121st edition), Table 144. Washington, D.C.: U.S. Government Printing Office. 
Wallerstein, J.S. and J.B. Kelly. 1980. Surviving the Breakup: How Children and Parents Cope with Divorce. New York: Basic Books.

Wolfinger, Nicholas H. 2005. Understanding the Divorce Cycle: The Children of Divorce in Their Own Marriages. New York: Cambridge University Press. . 2011. "More Evidence for Trends in the Intergenerational Transmission of Divorce: A Completed Cohort Approach Using Data from the General Social Survey." Demography 48:581-592. 
Table 1. Observed and Predicted 30 Year Cumulative Divorce Rates, by Marriage Cohort.

\begin{tabular}{|c|c|c|c|c|c|}
\hline & $\begin{array}{c}\text { Marriage } \\
\text { cohort }\end{array}$ & $\mathrm{N}$ & $\begin{array}{c}\text { Observed } \\
\text { rate }\end{array}$ & $\begin{array}{c}\text { Predicted } \\
\text { rate } \\
\end{array}$ & Difference \\
\hline \multicolumn{6}{|l|}{10 year forecasts } \\
\hline & $\begin{array}{l}1942-49 \\
1950-59 \\
1960-69\end{array}$ & $\begin{array}{c}709 \\
4,567 \\
7,084\end{array}$ & $\begin{array}{l}28 \% \\
29 \% \\
41 \%\end{array}$ & $\begin{array}{l}18 \% \\
21 \% \\
35 \%\end{array}$ & $\begin{array}{c}10 \\
8 \\
6\end{array}$ \\
\hline \multicolumn{6}{|l|}{15 year forecasts } \\
\hline & $\begin{array}{l}1942-56 \\
1950-64 \\
1955-69\end{array}$ & $\begin{array}{l}3,296 \\
7,692 \\
9,820\end{array}$ & $\begin{array}{l}27 \% \\
33 \% \\
38 \%\end{array}$ & $\begin{array}{l}23 \% \\
29 \% \\
34 \%\end{array}$ & $\begin{array}{l}4 \\
4 \\
4\end{array}$ \\
\hline
\end{tabular}


Figure 1. The Sickle Model of Duration Dependence $(a=1, b=2)$.

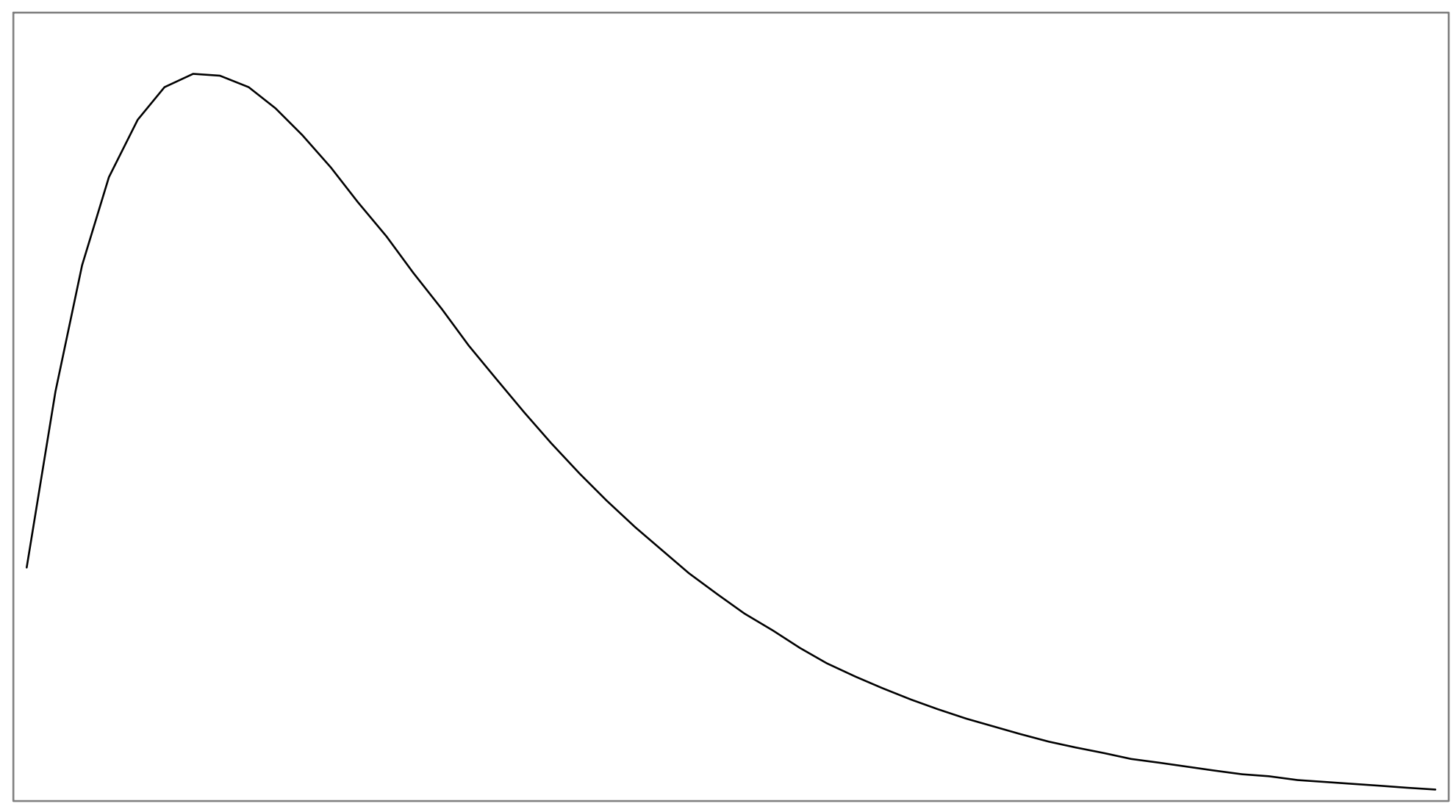




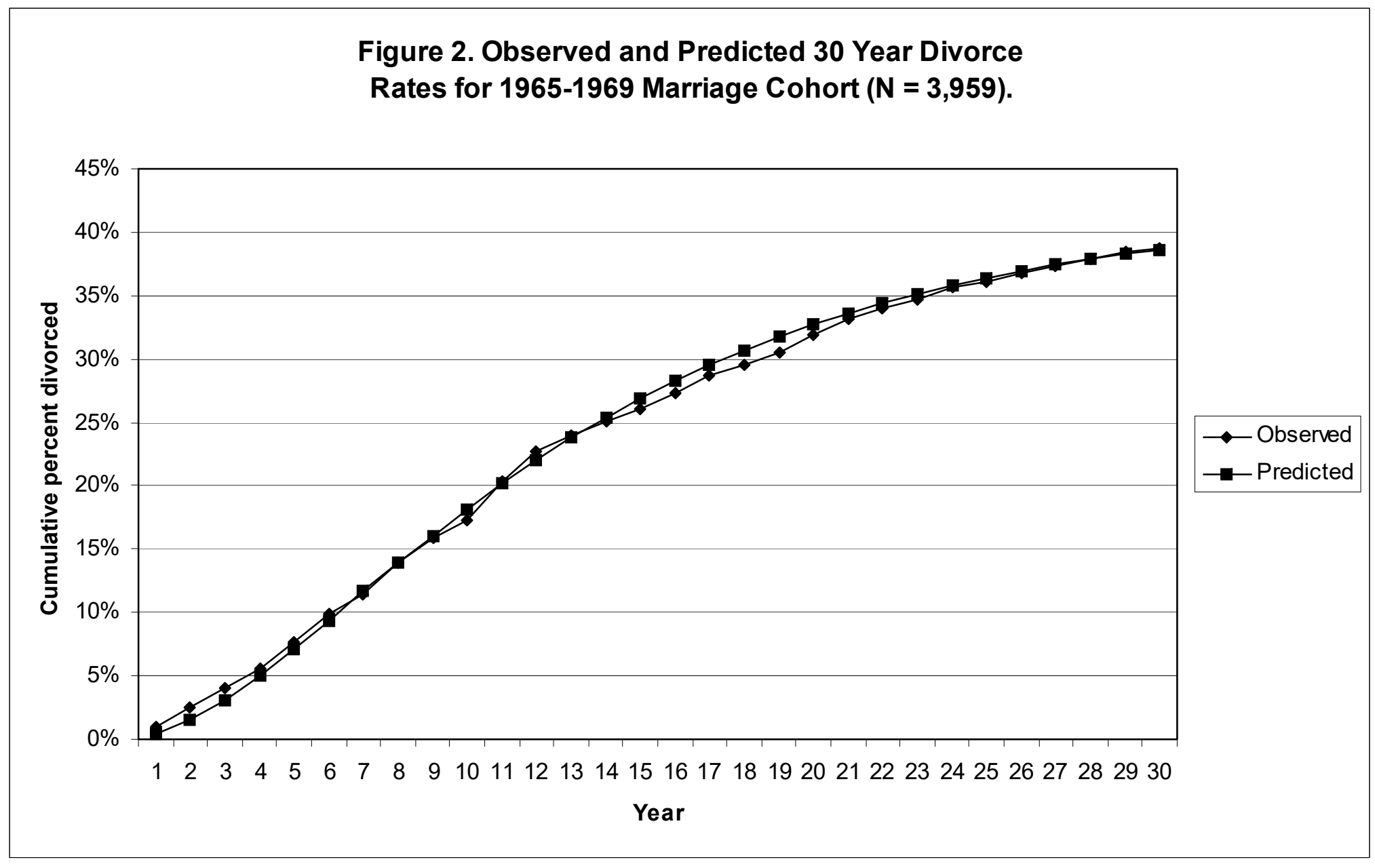


Fi 3. Sickle Model Forecasts of Current 30 Year Divorce Rates.

Forecast based on 1991-1995 marital histories $(\mathrm{N}=4,035)$

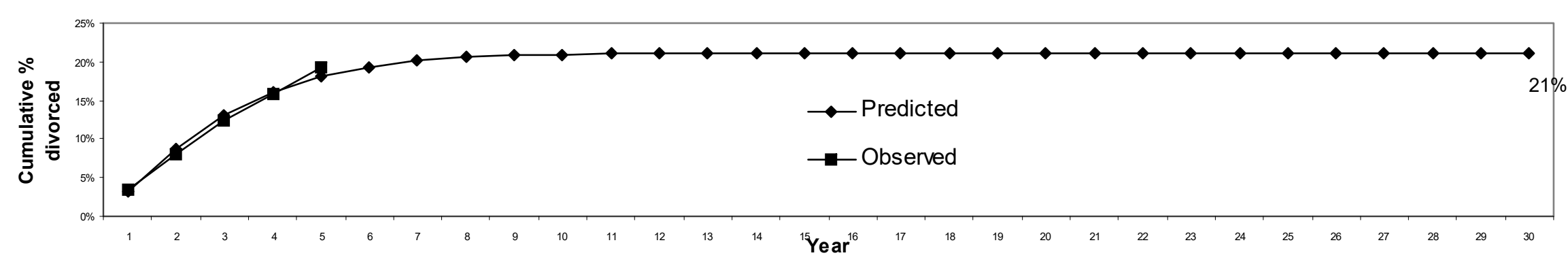

Forecast based on 1986-1995 marital histories $(\mathrm{N}=8,287)$

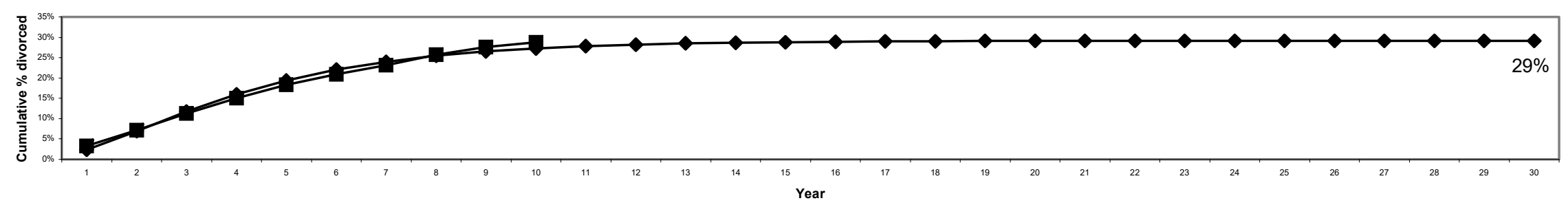

Forecast based on 1981-1995 marital histories $(\mathrm{N}=12,697)$

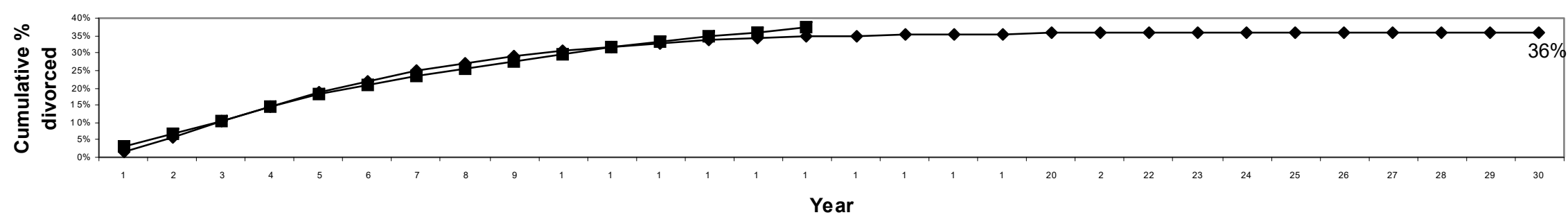

